\title{
The Influence of Network Real-name System on the Management of Internet Public Opinion
}

\author{
Song Guangxing ${ }^{1}$, Yang Pingfang ${ }^{2}$ \\ ${ }^{1}$ School of Public Management, Yunnan University of Finance and Economics, Kunming, P.R.China \\ (gxsong_yn@163.com) \\ ${ }^{2}$ School of International Business, Yunnan University of Finance and Economics, Kunming, P.R.China \\ (yangpingfang@163.com)
}

\begin{abstract}
With the rapid development of network and information technology, virtual society, as the extention of reality society, has been becoming an important platform of people's political participation and daily life. More and more netizens begin to use the Internet to express their ideas and appeals. Internet real-name system, as a way to normalize network behaviors and purify network environment, is playing an important role. This paper looks back the development of Internet real-name system, analyzes both positive and negative effects of the network real-name system on the management of Internet public opinions, and makes some suggestions for the implementation and promotion of the network real-name system in China.
\end{abstract}

Keywords: Virtual Society, Internet Public Opinion, Internet Real-name System

\section{Introduction}

In recent yeas, the technology of information and network has been developing rapidly, and the number of Internet users has been increasing continuously. The statistical investigation results of China Internet Network Information Center (CNNIC) showed that the popularity rate of Internet in China had reached $42.1 \%$ by the end of 2012, and the total number of netizens has increased to 564 millions.

With the increase of Internet popularizing rate, the Internet has become an important channel for people to participate in political and social activities, and network public opinion has the trend to become the center of social opinion field. In other words, The Internet is gradually become the source, the distributing center and the main battle field of social opinions. Especially, the characteristics of microblog's instantaneity, convenience and fast spreading further promote the development of network public opinions, and the public opinion on the microblogs also becomes one of the most influential network public opinions. Network public opinion is of the characteristics of abundance information, instantaneity, rapid propagation, and wide range of influence, etc. It is a double-edged sword, i.e. it has positive and negative effects on the society. It can promote the settlement of social events, and encourage the government department to improve their working style. However, it may easily cause mass incidents, even be easily used by hostile forces. At present, network public opinions may become a propelling power for social management of the governments. All levels of governments can use the Internet to establish better relationship between the government and the public. On the contrary, if the governments pay less attention on network public opinions or 
fail to make correct decisions on their management and guidance, the direct result is that it would be make affairs worse and block the work of social management of the governments. As the network public opinion has extensive influences, it has become a new hotspot of the network security field which the government and academia pay more attention. In this sense, it is very important to strengthen the guidance of network public opinions.

Internet real-name system is a kind of mode to manage the Internet. It means that before people use network services, they should provide their identity information to the managers of the network, and the managers confirm and manage the users' identities and IP at the background. The implementation of network real-name system can strengthen self-discipline of network users, and reduce network crime rate, so it is helpful for purifying the network environment, maintaining normal order of the Internet and increasing the safety of online transactions.

Many scholars in science and engineering have participated in the research on network real-name system from technical level, making many theoretical conceits realized and applied. The application of computer technology and mathematical knowledge such as digital identification, fingerprint certification and digital watermark provides specific implementation technologies and methods for network real-name system, which greatly improves the trust of the public on network real-name system.

Yan Su et.al (2011) put forward a method of situation analysis of the network public opinion which was based on the variable-weighted Choquet fuzzy integral. Ji Dan et.al (2012) identified the course of development of the study of network public opinions in the past ten years in China and pointed out the common problems in the current studies of network public opinions. They argued that the researches on network public opinion included its concept, its influences, the management mechanism and guiding strategies of network public opinion, and the index system and technology for monitoring it. Wang Fengyan et. al (2010) built a conceptual model of the relationship between perceived quality, trust, extrinsic motivation, intrinsic motivation and usage in the virtual communities with real-name system, and the empirical analysis showed that perceived quality, trust, extrinsic motivation and intrinsic motivation all significantly influenced usage. Additionally, perceived quality has a positive correlation with trust. The network real-name system is characterized by technical and tool properties and ethical significance, thus limiting the function of it.(Zhang Jianwen, 2012).

In this paper, we first retrospect the current status of network real-name system abroad and in China, then analyze the influences of it on the management of Internet public opinions.

\section{Current Situation of the Implementation of Network Real-name System}

\subsection{Network Real-name System abroad}

With the advent of the Internet age, the network brings convenience and at the same time causes many problems to people. Network violence and privacy leakage occurs frequently. Therefore, many countries are carrying out network real-name system in order to purify the Internet environment. The network real-name system has enforced for a long time, but the implementation and effect have a great gap in different countries and there are also different problems in the process of implementation.

France implemented Law of Hadobby to regulate and manage the network behaviors of the public through various measures and educate juveniles about the importance of network safety. Swiss issued Convention on Cyber Crime to strengthen network regulation and management and effectively fight against cyber crime. America prevents cyber crime through a series 
of measures such as legislation, especially focuses on preventing the juveniles from the invasion of adverse network information. Although these countries have made significant achievements in the process of implementing network real-name system, it is still quite remote to realize the objective of thoroughly eradicating cyber crime and guaranteeing the sound development of network.

South Korea is the first country to implement network real-name system compulsorily and achieve success in the process of implementation up to 10 years. There are many aspects worthy of learning and referencing by China. First, compulsion is the rot means for South Korea to implement network real-name system successfully. Through measures such as legislation, South Korea implements real-name system to all network activities, and has become one of the countries with the most thorough real-name system. Second, the government of South Korea makes great efforts to publicize the advantages and benefits of network real-name system, so as to make people support the country to implement this system. Fourth, by promulgating relevant laws of different degrees in the long term, the government of South Korea implements network real-name system gradually, which is not only beneficial for the supervision department to continuously perfect the supervision and management measures, but also beneficial for the masses to understand and support network real-name system.

Although South Korea has made significant achievements in implementing network real-name system, there also exist many problems. For example, various major websites of South Korea are often attacked by hackers and many events of disclosure of users' personal information and breakdown of online trading system have occurred. Therefore, while implementing the network real-name system, our government must guarantee the citizens' personal information effectively, otherwise, serious government credit crisis will occur.

\subsection{Network Real-name System in China}

In the beginning of 2003, real-name registration system started to impose in all Internet bars in China. In the next year, real-name system started to be used in BBS on the education network websites of universities and colleges. In May, 2004, the draft of Internet E-mail Service Standards by China Internet Association stipulated that all providers for e-mail services should ask the customers to provide their true materials. In March, 2005, Ministry of Information Industry of the PRC issued the Regulation of Record Management for Non-profitable Internet Information Service, and required all non-profitable personal websites to carry out real-name registration system. In July, 2005, Shenzhen Bureau of Public Security asked the founders and administrators of QQ groups to carry out real-name registration system. This action was regarded as the prelude of carrying out the network real-name system in China.

On May 1, 2009, Regulations on the Protection and Management of Computer Information and Network Security started to work in Hangzhou City, which symbolized the network real-name system was issued as local legislature for the first time.

After nearly three years' controversial implementation, network real-name system finally realized a breakthrough progress. In December 2012, Decision of the Standing Committee of the National People's Congress on Strengthening Network Information Protection was deliberated and passed in the $30^{\text {th }}$ session of the Standing Committee of the $11^{\text {th }}$ National People's Congress, in which the provisions on users' providing real identification when handling network access formalities raised network real-name system to the height of national laws, making real-name system become forcible restriction measure. However, this system is not the same as that of South Korea.

In China, the implementation of network 
real-name system is still at the preliminary stage and the feasibility is to be discussed. First, as the technology of network real-name system such as digital identification and fingerprint certification is not mature now. Implementing network real-name system can rather than restrict cyber crime effectively, but in turn it will add excessive cost for cyber crime investigation and punishment. Second, the conditions for implementation of network real name-system are insufficient, for example, the legislation of China is imperfect, the recognition of the public is not high and there exists severe disclosure of personal privacy, so it is quite difficult to supervise and manage the network thoroughly. Third, as network is one of the approaches for the masses to express their opinions, implementing network real-name system often restricts the netizens' freedom of speech, causing the repelling and objection of the masses to network real-name system. Finally, although China has introduced laws and regulations about network real-name system, they are not paid highly attention by relevant departments, so the implementation effect is not so obvious. Moreover, insufficient publicity and improper method are also one of the reasons for extremely poor effect of promotion of network real-name system in China.

In a word, the implementation of network real-name system is at the preliminary stage both at home and abroad with coexistence of achievements and problems. China, being behind in the implementation of network real-name system, should learn more from the excellent foreign experiences and study advanced technologies, but meanwhile, should pay attention to the problems occurring in other countries and avoid detours as far as possible to strive to take a sound and stable road of real-name system.

\section{Influences of Network Real-name System on the Management of Network Public Opinion}

Public opinions expressed on the Internet spread faster and at a wider range than on traditional media. So it is more difficult to supervise and control network public opinions. How to correctly guide them is an important topic and a challenge. Carrying out network real-name system is a necessary way to monitor the Internet and guide network public opinions. However, since it involves in the problems of freedom of speech and privacy protection, people have been debating on this system all the time. Some people advocate establishing a network environment with true identities, but others argues that we should keep anonymity. In fact, there is no perfect system. Network real-name system has positive and negative impacts on the management of network public opinions.

\subsection{Raising the Self-discipline Consciousness of the Netizens}

More and more harmful information spreads on the Internet, so people from different fields begin to doubt the anonymous dissemination of the information. For the illegal actions such as using the Internet to express freedom and harmful information, we can use technical and law means to investigate and affix the responsibility for them, however, many evidences have proved that anonymity does increase the difficulties and costs for relevant departments to investigate these cases.

Network real-name system requires the netizens to provide their personal true identity information, thus we can match virtual subject and its actual subject. Network real-name system is designed to limit irresponsible or even illegal speeches and actions, and this is a dominant trend in the field of network all over the world. By using network real-name system, we can encourage the netizens to restrict their actions 
more strictly, and to be more responsible for their network speeches and to act more rationally. In a word, it is helpful for forming responsible citizen consciousness, raising the level of social hazard, reducing network crimes, and finally purifying the environment of the Internet. At the same time, it is also helpful for lowering the expense of dealing with releasing false information on the Internet and infringing on people's privacy. In fact, after putting network real-name system into effect in South Korea, the gossip and violent speeches in the Internet drops, and the responsibility and self-discipline consciousness has been strengthened.

\subsection{Restricting the Public Speech to Some Extent}

China is now at the period of social transformation, and social contradictions are relatively distinctive, while the channels of expressing views are also limit, so the Internet becomes the main channel for the public (especially the vulnerable group) to express their appeals. If we imposed network real-name system, the space of expression on the Internet would be contracted and the protection of the netizens' speeches would be reduced.

On the other hand, report through the Internet is welcome. The fundamental reason is that most of these reports are anonymous, thus the reporters needn't to worry about being revenged. Network real-name system may destroy the atmosphere of network monitoring, and increase the risk of report by the Internet. From this perspective, network real-name system goes against anti-corruption.

In short, some people worry about the implementation of network real-name system will derive them from freedom of speech, so they do not agree to this system.

In fact, this problem can be solved by the way of real-name at the background and anonymous in the foreground. For example, South Korea specifies that after passing the identification verification, the netizens can use their codes and aliases etc, to issue information on the Internet, which guarantees the personal privacy and freedom of expression and relieves the resistance of the masses, making real-name system proceed smoothly.

Another way to lower the negative effects of real-name system on speech is to use limit real-name. It can solve the contradiction between the control of the government and the expansion of appeals of the Internet users. In other words, we can carry out anonymous and real-name system simultaneously.

For example, anonymity maybe permitted on the microblogs and QQ group. But in e-commerce and e-government, real-name system should be used. We can use real-name system to normalize commercial actions. The goal of using real-name system in Facebook is to push the development of e-commerce. In e-commerce, real-name system for the sellers is helpful for establishing reputation and promoting transactions. Once a dispute between the seller and the buyer happens, they can solve it through the way of law. The development of e-government makes more services of the governments complete on the Internet. So we should carry out network real-name system to maintain the credibility of the government. A survey conducted by the citizen box in Shanghai shows that $9.62 \%$ of the interviewees hoped to realize network real-name system so as to handle affairs online safely.

\subsection{Resulting Leakage of Personal \\ Information and Privacy of Users}

At present, relevant laws and institutions are not perfect, and network technologies are not mature, thus the implementation of network real-name system may result in the leakage of personal information and the invasion of personal privacy.

For the network real-name system of South Korea, websites can hold identity information of the users. Moreover, the users must provide authentication codes and identity number before 
they use Internet services. Some websites have weak measures to protect users' information, so they are easy to be attacked by the hackers, which often resulting in the leakage of identity information. It was reported by the media in July, 2011 that a portal site named Nate was attacked by the hackers, and resulted in the leakage of the information of 35 million users. The information included user names, their full names, and telephone numbers, which had not been encrypted, and e-mail addresses, and encrypted keywords and identity numbers. Therefore, in order to reduce the actions of illegal collection of personal information in the Internet, South Korea government decided to abolish network real-name system step by step.

As a new system, the provisions on users' providing real identification in China put the protection of personal information on the most important position. Firstly, the users directly provide identity information to the certification authority through the Internet, avoiding leaving their information on the websites. So data leakage due to weak measures of protecting information is also avoidable. Secondly, it is convenient for monitoring and managing to take national authoritative institutions as identity authentication institutions. China Internet Association has built a unified platform of Internet identity authentication. It is a third party which connects websites and national service center for inquiring identity card numbers. China Internet Association is a non-profitable organization attached to The Ministry of Industry and Information Technology, so it is convenient to monitor and mange this organization. This is an important guarantee for personal information security.

\section{Conclusions}

Internet is a double-edged sword, it provides new channel for all citizens to express their ideas, opinions and appeals, and become a platform of anti-corruption. However, it has also cause network violence and crimes, which harms people's legal rights, social harmony, and the national interests. Using the real-name system to regulate the internet access is an efficient way to promote people's self-discipline against internet crime. It is beneficial to the management of network public opinions. But people think it will cause personal information risks and limit the freedom of speech. In the long run, enforcing network real-name system is an undoubtable trend. In China, the conditions of implementing network real-name system extensively and thoroughly are now not mature. So we should gradually carry out the real-name system, and perfect related laws, regulations, and website technology. Moreover, we may learn more from the experiences and lessons of network real-name system in South Korea and other countries. At present, he mode of real-name at the background and anonymous in the foreground is a feasible solution.

\section{References}

[1] China Internet Network Information Center (CNNIC). Statistical Report on the Development of the Internet in China (2013-01). http://www.Cnnic.net.cn

[2] Deng Juntao, Niu Zhongjiang. Current Status of Network Public Opinions in China and Contermeasures. People's Forum, 2012, 7: 128-129.

[3] Ji Dan, Xie Yungeng. Retrospection and Introspection on the Study of Network Public Opinions in China. Journal of Shanghai Jiaotong University (Philosophy and Social Science). 2012, 20(4): 48-56.

[4] Liu Dazhi. Analysis on Network Real Name System from the Perspective of Public Policy-Also on Internet Management Concept. Journal of Chongqing Institute of Technology ( Social Science Edition). 2007, 21(8): 40-43.

[5] Meng Xiangxiu. Implementation of Network Real-name System in China. Journal of Harbin University, 2012, 33(6): 61-65.

[6] Su Yan et.al. The Situation Analysis of the Network Public Opinion Based on the Variable-Weighted Choquet Fuzzy Integral. Proceedings of the 2011 International Conference of Information Technology, Computer Engineering and Management 
Sciences. Sep. 2011: 219-225.

[7] Wang Fengyan et.al. Influencing Factors of Usage in Virtual Communities with Real-Name System: An Empirical Research. Proceedings of the 3rd International Conference on Information Management, Innovation Management and Industrial Engineering. Nov. 2010: 662-665.

[8] Zhang Jianwen, Luo Liuhu. The Difference of Spirit of Network Real-name Institution between China and Korea and Renewal of Ideas of Network Management. Journal of Chongqing University of Posts and Telecommunications (Social Science Edition). 2012, 24(3): 23-30. 